\title{
Técnicas matemáticas na redução de mecanismos cinéticos com ilustra- ção para chamas do metano
}

\author{
Mathematical techniques in obtaining reduced kinetic mechanisms with illustration for \\ methane flames
}

\author{
César Bublitz e Álvaro Luiz de Bortoli ${ }^{2}$ \\ 1,2 Universidade Federal do Rio Grande do Sul-UFRGS, Porto alegre, RS, Brasil \\ cesarb89@gmail.com; dbortoli@mat.ufrgs.br
}

\begin{abstract}
Resumo
O tratamento de mecanismos cinéticos de reação detalhados de combustão é muito caro computacionalmente, principalmente quando o objetivo é a implementação de modelos de CFD (Dinâmica de Fluidos Computacional); por isso, grande esforço na procura por métodos de redução de mecanismos tem sido observado. Na busca por técnicas eficientes, várias ideias e teorias surgiram nos últimos anos. Análise de sensibilidade, lumping e DRG (Directed Relation Graph) são algumas dessas técnicas, as quais parecem ser ferramentas poderosas que podem ajudar neste desafio. Este trabalho mostra estas estratégias, descrevendo de maneira objetiva suas aplicações na redução de mecanismos de reação. Um mecanismo reduzido para chamas do metano consistindo de seis etapas entre nove espécies reativas é obtido a partir do mecanismo esqueleto, o qual consiste de 25 reações.
\end{abstract}

Palavras-chave: Combustão. Redução de mecanismos. Mecanismo esqueleto. Autovalores.

\begin{abstract}
The computational treatment of detailed kinetic reaction mechanisms of combustion is very expensive, especially when the objective is the implementation of CFD (Computational Fluid Dynamics) models; therefore, major effort in searching for methods of mechanisms reduction has been observed. In the pursuit of efficient techniques, various ideas and theories have emerged in recent years. Sensitivity analysis, lumping and DRG (Directed Relation Graph) are some of these techniques, which seem to be powerful tools that can assist in this challenge. This paper shows these strategies, objectively describing their applications on reduction of reaction mechanisms. A reduced mechanism for methane flames consisting of six-step among nine reactive species is obtained from the skeletal mechanism, which consists of 25 reactions.
\end{abstract}

Keywords: Combustion. Mechanisms reduction. Skeletal mechanism. Eigenvalues. 


\section{Introduction}

Researchers have explored computational methods to develop practical combustion systems, especially as regards the reduction of the emission of pollutants into the atmosphere (Griffiths, 1995; Andreis and De Bortoli, 2012). To understand the chemical energy conversion (stored in fuels) in thermal energy through chemical reactions, a lot of effort has been applied in the development of detailed and reduced reaction mechanisms to the combustion of different chemical compounds.

Computer simulations with detailed kinetic mechanisms are more complicated due to the existence of highly reactive radicals, which induces a significant stiffness in the system of governing equations due to differences, of several orders of magnitude, in timescales of conversion between species. Consequently, there is the need to develop, from these detailed mechanisms, the corresponding reduced mechanisms with fewer variables and moderate stiffness, maintaining a good level of accuracy and comprehensiveness of the detailed kinetic mechanisms ( $\mathrm{Lu}$ and Law, 2006a; PepiotDesjardins and Pitsch, 2008a; Andreis et al., 2013).

Another drawback of detailed mechanisms is the difficulty of obtaining accurate values of reaction rates for the large number of elementary reactions that form a complete mechanism, and, in this way, the uncertainty in the values of each parameter can lead to greater uncertainty in the predictions made with a complete mechanism than those obtained with reduced mechanisms (Martins, 2011). So, in computational context, becomes convenient to work with reduced mechanisms.

In addition, problems involving reactive flows require handling the set of reactive NavierStokes equations, which are coupled with the equations of chemical reactions and are highly non-linear (Peters and Rogg, 1993; De Bortoli, 2000). In this way, it becomes necessary to develop reduced kinetic mechanisms, and a mathematical approach on the subject can assist and/or make this task more efficient.

The most widely used method for mechanisms reduction, and perhaps with more convincing results, is the steady state assumption (QSSA), valid for intermediate species produced by slow reactions and consumed by fast reactions, so that the concentration of these species remains small (Turns, 2000). This hypothesis allows the elimination of some species and the subsequent conversion of differential equations into algebraic equations.

However, for finding a procedure that could be applied to a huge number of reaction systems and to automate the process of reduction, there is the need to use various mathematical tools. Several theoretical methods have been developed and gradually are being applied to the reduction of kinetic mechanisms. Among them are lumping, sensitivity analysis and DRG.

The lumping theory was developed by Wei and Kuo (1969a; 1969b) for monomolecular systems and, after, for any reaction system by $\mathrm{Li}$ and Rabitz (1989; 1990). The technique is purely mathematical, and consists in the reduction of a differential equations system, which is projected in a smaller system from a full rank matrix.

The sensitivity analysis investigates the effect of parameter change in the solution of mathematical models. Although there are previous works on the technique, with regard to its application in combustion, one can take as a basis the work of Turányi (1990), who developed a large and concise approach on the subject.

The DRG method, developed recently by $\mathrm{Lu}$ and Law (2005; 2006a; 2006b), is addressed to generating skeleton mechanisms from detailed mechanisms. The approach consists in determining the coupling degree among species of a kinetic mechanism, in order to eliminate redundant species, compared with the species considered important.

This paper gives a summary of the techniques mentioned above, to keep the focus on their application in reduction of mechanisms. After exposing in general terms the theory, important considerations about each technique will be given, and a reduced mechanism for methane flames will be obtained.

\section{Mechanisms reduction}

A chemical kinetic problem can be written as

$$
\frac{d \boldsymbol{c}}{d t}=\boldsymbol{f}(\boldsymbol{c}, \boldsymbol{k}), \quad \boldsymbol{c}(0)=\boldsymbol{c}^{0}
$$


where $\boldsymbol{c}$ is the concentrations vector and $\boldsymbol{k}$ the vector which each component is the specific rate $k_{i}=A T^{\beta} e^{-E \alpha /(R T)}$ of reaction $i$ (Turányi, 1990; Tomlin et al., 1998; Kuo, 2005; De Bortoli et al., 2015), being $A$ the frequency factor, $T$ the temperature (in Kelvins), $\beta$ the temperature exponent, $E a$ the activation energy (in $\mathrm{cal} / \mathrm{mol}$ ) and $R$ the gas constant (in $\mathrm{cal} /(\mathrm{mol} \cdot \mathrm{K})$ ).

The simplest and most straightforward strategy in mechanisms reduction is to identify and remove species and reactions that have negligible contributions in the combustion process (Pepiot-Desjardins and Pitsch, 2008a). For this purpose, the simplest and most widely used technique is quasi steady state assumption (QSSA), but, as previously mentioned, it would be interesting to complement such approach with other techniques such as shown successfully by, for example, Andreis and De Bortoli (2012); Andreis et al. (2012) and Andreis et al. (2013) in recent papers, where the steady state assumption is combined with the partial equilibrium hypothesis.

\subsection{Lumping}

As described and proved in detail by Li and Rabitz (1989), in the exact lumping approach, one ODE's system, given by equation (1), is projected into a smaller system using a matrix $M$, i.e.,

$$
\frac{d \boldsymbol{c}}{d t}=\boldsymbol{f}(\boldsymbol{c}) \Rightarrow \frac{d \hat{\boldsymbol{c}}}{d t}=M \frac{d \boldsymbol{c}}{d t}=M \boldsymbol{f}(\boldsymbol{c})=\hat{\boldsymbol{f}}(\hat{\boldsymbol{c}}) .
$$

Differentiating the presented ODE's system with respect to $k_{j}$ (Tomlin et al., 1998; Turányi and Tomlin, 2014; De Bortoli et al., 2015), one obtains

$$
\frac{d\left(\partial \boldsymbol{c} / \partial k_{j}\right)}{d t}=\frac{\partial \boldsymbol{f}}{\partial \boldsymbol{c}} \cdot \frac{\partial \boldsymbol{c}}{\partial k_{j}}+\frac{\partial f}{\partial k_{j}}=J(\boldsymbol{c}) \cdot \frac{\partial \boldsymbol{c}}{\partial k_{j}}+\frac{\partial \boldsymbol{f}}{\partial k_{j}},(2)
$$

where $I(\boldsymbol{c})$ is the Jacobian matrix associated with the system.

As combustion kinetic mechanisms are frequently represented by non-linear systems, the matrix $A=\sum_{i=1}^{n} A_{k}$ is mounted from the decomposition

$$
I^{T}(\boldsymbol{c})=A_{0}+\sum_{i=1}^{n}\left[a_{i}(\boldsymbol{c}) \cdot A_{i}\right] .
$$

which sometimes is simplified as

$$
I^{T}(\boldsymbol{c})=A_{0}+\sum_{i=1}^{n} c_{i} A_{i} .
$$

Some eigenvectors (or linear combinations of them) of $A$ will compose the rows of the lumping matrix $M$ and the amount of vectors used determines the size of the reduced mechanism. Generalized eigenvectors can be used when the matrix $A$ is not diagonalizable.

The task in lumping is, taking into account all possible subspaces generated from eigenvectors (and possibly generalized eigenvectors), determine $l^{T}(\boldsymbol{c})$-invariant subspaces by selection of the subspaces that are simultaneously invariant under all $A_{k}$ 's. This is the simplest way to find the lumping matrices $\mathrm{M}$, and the system depicting the lumped species is given by $d \hat{\boldsymbol{c}} / d t=\operatorname{Mf}(\bar{M} \hat{\boldsymbol{c}})$, where $\bar{M}$ is any generalized inverse of $M$ satisfying $M \bar{M}=I$. There is another approach to find the lumping matrices, being suggested to the reader interested in details and demonstrations the bibliographies Wei and Kuo (1969a; 1969b) and Li and Rabitz (1989; 1990).

From the viewpoint of combustion engines, however, the mathematical restrictions imposed by the exact lumping can be very stringent, or, in the case of approximate lumping may cause lumped systems that do not follow unimolecular and/or bimolecular reaction schemes ( $\mathrm{Li}$ and Rabitz, 1990). Another issue is the great number of possibilities for the matrices $M$ and $M^{-1}$, making it necessary to use some physical information to determine, in a simple way, a matrix that reduces the system to a desired level. For instance, a generalized inverse can be approximately found using information related to the system time-scales (Whitehouse et al., 2004b).

With less mathematical formality, chemical lumping methods group species with similar composition, functionalities, or evolutionary history into representative lumped species or pseudo species, so the overall number of species is reduced (Pepiot-Desjardins and Pitsch, 2008a; Shi et al., 2010). The crucial issues in this approach are (Huang et al., 2005; Turányi and Tomlin, 2014):

- determine which species are to be lumped; 
- classify how the selected species should contribute to the lumped species; and

- estimate kinetic parameters for the lumped species.

Lumping based on chemical similarities results in new variables which are simply linear sums of the original species concentrations, i.e., it is just a special case of linear lumping (Tomlin et al., 1998; Turányi and Tomlin, 2014). A detailed review of chemical lumping methods and their applications can be found in Ranzi et al. (2001) or in the recent paper of Stagni et al. (2014).

\subsection{DRG (Directed Relation Graph)}

The DRG method, as shown by Lu and Law (2005), is a quick and simple tool for eliminating redundant species in detailed mechanisms. The importance of a species in the mechanism is determined by the influence of its removal on principal species (An and Jiang, 2013). In a graph representation, each point (vertex) represents a species and there exists an edge from $A$ to $B$ $(A \rightarrow B)$ if and only if the elimination of species $B$ may directly induce significant error in the production rate of species $A$.

In a mechanism with $n$ elementary reactions, the coefficient $r_{A B}$, which quantifies the normalized contribution of species $B$ for the production rate of species $A$ (Lu and Law, 2005; 2006a; 2006b), is defined by

$$
r_{A B}=\frac{\sum_{i=1}^{n}\left|v_{A, i} w_{i} \delta_{B i}\right|}{\sum_{i=1}^{n}\left|v_{A, i} w_{i}\right|},
$$

where $\delta_{B i}$ take the value 1 if the $i$-th elementary reaction involve species $B$ and the value 0 otherwise. There are other forms to write the DRG method, such as

or

$$
r_{A B}=\frac{\sum_{i=1}^{n}\left|v_{A, i} w_{i} \delta_{B i}\right|}{\left|\sum_{i=1}^{n} v_{A, i} w_{i}\right|}=\frac{\sum_{i=1}^{n}\left|v_{A, i} w_{i} \delta_{B i}\right|}{\left|w_{A}\right|}
$$

$$
r_{A B}=\frac{\sum_{i=1}^{n}\left(\left|v_{A, i} w_{f i}\right|+\left|v_{A, i} w_{r i}\right|\right) \delta_{B i}}{\sum_{i=1}^{n}\left|v_{A, i} w_{f i}\right|+\sum_{i=1}^{n}\left|v_{A, i} w_{r i}\right|},
$$

with their characteristics, as discussed by $\mathrm{Lu}$ an Law (2006b).

For an important species $A$, the aim is to eliminate from the mechanism species in which $r_{A B}<\varepsilon$, where $\varepsilon$ is a specified limit. Figure 1 illustrates a situation where $A$ depends on $B$, but
$B$ does not depend on $A$, and if $A$ is considered an important species, the species that should be maintained would be $\mathrm{B}$ and $\mathrm{D}$, the latter due to its strong coupling degree with the necessary species $B$ indicated by the width of the edge.
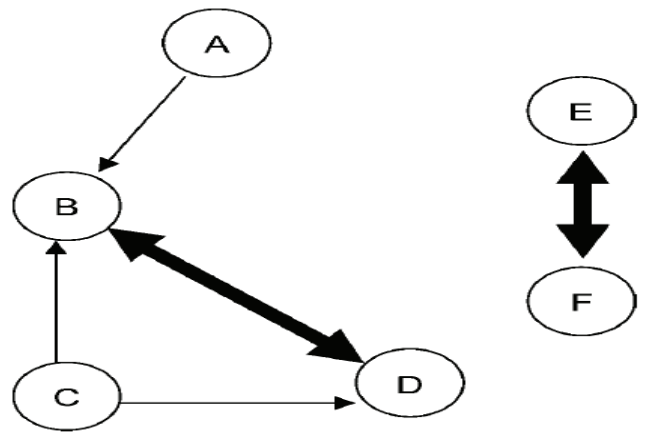

Figure 1: DRG showing coupling between species (Lu and Law, 2005).

Variations of the DRG are also being developed, such as the DRGEP (Directed Relation Graph with Error Propagation) and the DRGASA (Directed Relation Graph Aided Sensitivity Analysis). In the first, the assumption that all coupled species are equally important in the mechanism is lost, by considering that error propagates along the graph from the initially selected important species (Pepiot-Desjardins and Pitsch, 2008b; Niemeyer et al., 2010; Turányi and Tomlin, 2014), while the DRGASA is the DRG technique complemented by simulations that measure the consequences of eliminating species one by one (Zheng et al., 2007; Turányi and Tomlin, 2014).

\subsection{Sensitivity analysis}

The group of methods for the study of parametric information in mathematical models is called sensitivity analysis, which investigates the relationship between the parameters and the output of any model (Turányi, 1997; Tomlin et al., 1998). Here, the idea is to consider such approach applied to the system (1), observing the coupled system (2), with respect to parameters $k_{i}$.

Since the reaction rates from reactions of different orders have different units, the sensitivity coefficients of local concentration $\partial c_{i} / \partial k_{j}$ become incomparable, requiring the normalization

$$
S_{i j}=\frac{k_{j} \partial c_{i}}{c_{i} \partial k_{j}}=\frac{\partial \ln c_{i}}{\partial \ln k_{j}},
$$


where $S_{i j}$ represents the fractional change in concentration $c_{i}$ caused by fractional parameter change (Turányi, 1990; 1997; Tomlin et al., 1998).

When one is interested in the effect of the parameter change in the concentrations of various species, the overall sensitivity

$$
B_{j}=\sum_{i}\left(\frac{\partial \ln c_{i}}{\partial \ln k_{j}}\right)^{2}
$$

can be considered, where $B_{j}$ represents the effect in concentration of the species present in the summation in time $t$, caused by the change in the parameter $k_{j}$ (Whitehouse et al., 2004a; Turányi and Tomlin, 2014). But, for mechanisms reduction, is more utilized the relation

$$
B_{i}=\sum_{j}\left(\frac{c_{i}}{f_{j}} \frac{\partial f_{j}}{\partial c_{i}}\right)^{2} .
$$

However, the reduction task seems to be more efficient when applying principal component analysis (PCA). PCA is a mathematical method that evaluates the effect of simultaneous changing parameters on outputs of a model (Vajda et al., 1985; Tomlin et al., 1998). In this case, the idea is to work with the eigenvalues and eigenvectors analysis of a function that involves sensitivity matrices, being more common to work with the ratio of the rate of formation or consumption of species $i$ in reaction $j$ (or net rate of concentration change of the species $i$ ) (Turányi, 1990), given by

$$
F=\frac{\partial \ln f_{i}}{\partial \ln k_{j}}=\frac{v_{i j} w_{j}}{f_{i}}
$$

where each $v_{i j}$ stands for a stoichiometric coefficient and $w_{j}$ for the rate of reaction $j$.

By expressing $F^{T} F$ in terms of its eigenvalues and eigenvectors, are determined which reactions affect the necessary species most, since the eigenvectors reveal the coupling between reactions and the eigenvalues the weight of the corresponding eigenvector (Turányi et al., 1989; Huang et al., 2005). The aim then, is to remove the reactions with negligible contributions to the production rates of necessary species, since reactions with high eigenvector elements associated with higher eigenvalues are the most important ones (Whitehouse et al., 2004a).
The Jacobian analysis can also be used for reducing mechanisms and some points are discussed by Tomlin el al. (1998), and more recently by Turányi and Tomlin (2014). This include techniques based on an iterative procedure for the determination of the species that are more coupled with important species, or a simple analysis of the lifetime of the species, which can be based on the eigenvalues and eigenvectors of the Jacobian matrix.

\section{Results and discussion}

\subsection{Reduced Kinetic mechanism for methane}

A detailed mechanism for methane flames consists of about 300 elementary reactions among 50 species. Due to its easy application, the DRG method can be applied as a first reduction stage. Next, sensitivity analysis can be employed for obtaining further reduction, getting a skeletal mechanism for methane flames. In this case, the lumping approach may not be helpful, since it is used for the reduction of mechanisms for fuels with a higher number of isomers.

Here, for the skeletal mechanism of methane given by 25 reactions shown in Table 1 , a reduced mechanism is obtained by using some of the presented reduction strategies. The initial mechanism has 15 species and, with the help of the Jacobian analysis, six species are selected to be in steady-state. Consequently, a reduced mechanism of six-step among nine reactive species is obtained.

For the set of elementary reactions presented in Table 1, the balance equations can be written as

$$
\begin{gathered}
w_{O_{2}}=-w_{1}-w_{5}+w_{7}+w_{8}-w_{18}+w_{21} \\
w_{C H_{4}}=-w_{10}-w_{11}-w_{12} \\
w_{C O_{2}}=w_{9} \\
w_{H_{2} O}=w_{3}+w_{4}+w_{8}+w_{12}+w_{15}+w_{23}+w_{24} \\
w_{C O}=-w_{9}+w_{16}+w_{17} \\
w_{H_{2}}=-w_{2}-w_{3}+w_{7}+w_{11}+w_{14}+w_{16}+w_{19} \\
+w_{25} \\
w_{O H}=w_{1}+w_{2}-w_{3}-2 w_{4}+2 w_{6}-w_{8}-w_{9} \\
-w_{12}-w_{15}+2 w_{22}-w_{23}-w_{24} \\
w_{C H_{2} O}=w_{13}-w_{14}-w_{15}+w_{19}+w_{20} \\
w_{C H_{3}}=w_{10}+w_{11}+w_{12}-w_{13}-w_{18} \\
w_{H C O}=w_{14}+w_{15}-w_{16}-w_{17} \\
w_{O}=w_{1}-w_{2}+w_{4}-w_{13}+w_{18} \\
w_{H O}=w_{5}-w_{6}-w_{7}-w_{8}-2 w_{21}+w_{23} \\
w_{H}=-w_{1}+w_{2}+w_{3}-w_{5}-w_{6}-w_{7}+w_{9}+w_{10}
\end{gathered}
$$




$$
\begin{gathered}
-w_{11}+w_{13}-w_{14}-w_{16}+w_{17} \\
-w_{19}+w_{20}-w_{24}-2 w_{25} \\
w_{C_{3} O}=w_{18}-w_{19}-w_{20} \\
w_{H_{2} O_{2}}=w_{21}-w_{22}-w_{23}
\end{gathered}
$$

where $w_{S_{i}}=\frac{d\left[s_{i}\right]}{d t}=\frac{d c_{i}}{d t}$ is the production rate of species $S_{i}$ and $w_{j}$ represents the reaction rate. The positive sign of $w_{j}$ refers to a species which appears in the right side of the reactions of the Table 1, while the negative sign refers to a species in the left side of them (for reversible reactions, $w_{j}$ is the difference between the

\begin{tabular}{|c|c|c|c|c|}
\hline & Reaction & $A$ & $\beta$ & $E$ \\
\hline $1 f$ & $\mathrm{H}+\mathrm{O}_{2} \rightarrow \mathrm{O}+\mathrm{OH}$ & $2.0 \times 10^{14}$ & 0.0 & 16800 \\
\hline $1 b$ & $\mathrm{O}+\mathrm{OH} \rightarrow \mathrm{O}_{2}+\mathrm{H}$ & $1.575 \times 10^{13}$ & 0.0 & 690 \\
\hline $2 f$ & $\mathrm{O}+\mathrm{H}_{2} \rightarrow \mathrm{OH}+\mathrm{H}$ & $1.8 \times 10^{10}$ & 1.0 & 8826 \\
\hline $2 b$ & $\mathrm{OH}+\mathrm{H} \rightarrow \mathrm{O}+\mathrm{H}_{2}$ & $8.0 \times 10^{9}$ & 1.0 & 6760 \\
\hline $3 f$ & $\mathrm{H}_{2}+\mathrm{OH} \rightarrow \mathrm{H}_{2} \mathrm{O}+\mathrm{H}$ & $1.17 \times 10^{9}$ & 1.3 & 3626 \\
\hline $3 b$ & $\mathrm{H}_{2} \mathrm{O}+\mathrm{H} \rightarrow \mathrm{H}_{2}+\mathrm{OH}$ & $5.09 \times 10^{9}$ & 1.3 & 18588 \\
\hline $4 f$ & $\mathrm{OH}+\mathrm{OH} \rightarrow \mathrm{H}_{2} \mathrm{O}+\mathrm{O}$ & $6.0 \times 10^{8}$ & 1.3 & 0 \\
\hline $4 b$ & $\mathrm{H}_{2} \mathrm{O}+\mathrm{O} \rightarrow \mathrm{OH}+\mathrm{OH}$ & $5.9 \times 10^{9}$ & 1.3 & 17029 \\
\hline 5 & $\mathrm{H}+\mathrm{O}_{2}+\mathrm{M}^{\mathrm{a}} \rightarrow \mathrm{HO}_{2}+\mathrm{M}^{\mathrm{a}}$ & $2.3 \times 10^{18}$ & -0.8 & 0 \\
\hline 6 & $\mathrm{H}+\mathrm{HO}_{2} \rightarrow \mathrm{OH}+\mathrm{OH}$ & $1.5 \times 10^{14}$ & 0.0 & 1004 \\
\hline 7 & $\mathrm{H}+\mathrm{HO}_{2} \rightarrow \mathrm{H}_{2}+\mathrm{O}_{2}$ & $2.5 \times 10^{13}$ & 0.0 & 700 \\
\hline 8 & $\mathrm{OH}+\mathrm{HO}_{2} \rightarrow \mathrm{H}_{2} \mathrm{O}+\mathrm{O}_{2}$ & $2.0 \times 10^{13}$ & 0.0 & 1000 \\
\hline $9 f$ & $\mathrm{CO}+\mathrm{OH} \rightarrow \mathrm{CO}_{2}+\mathrm{H}$ & $1.51 \times 10^{7}$ & 1.3 & -758 \\
\hline $9 b$ & $\mathrm{CO}_{2}+\mathrm{H} \rightarrow \mathrm{CO}+\mathrm{OH}$ & $1.57 \times 10^{9}$ & 1.3 & 22337 \\
\hline $10 f$ & $\mathrm{CH}_{4}+\mathrm{M}^{\mathrm{b}} \rightarrow \mathrm{CH}_{3}+\mathrm{H}+\mathrm{M}^{\mathrm{b}}$ & $6.3 \times 10^{14}$ & 0.0 & 104000 \\
\hline $10 \mathrm{~b}$ & $\mathrm{CH}_{3}+\mathrm{H}+\mathrm{M}^{\mathrm{b}} \rightarrow \mathrm{CH}_{4}+\mathrm{M}^{\mathrm{b}}$ & $5.20 \times 10^{12}$ & 0.0 & -1310 \\
\hline $11 f$ & $\mathrm{CH}_{4}+\mathrm{H} \rightarrow \mathrm{CH}_{3}+\mathrm{H}_{2}$ & $2.2 \times 10^{4}$ & 3.0 & 8750 \\
\hline $11 b$ & $\mathrm{CH}_{3}+\mathrm{H}_{2} \rightarrow \mathrm{CH}_{4}+\mathrm{H}$ & $9.57 \times 10^{2}$ & 3.0 & 8750 \\
\hline $12 f$ & $\mathrm{CH}_{4}+\mathrm{OH} \rightarrow \mathrm{CH}_{3}+\mathrm{H}_{2} \mathrm{O}$ & $1.6 \times 10^{6}$ & 2.1 & 2460 \\
\hline $12 b$ & $\mathrm{CH}_{3}+\mathrm{H}_{2} \mathrm{O} \rightarrow \mathrm{CH}_{4}+\mathrm{OH}$ & $3.02 \times 10^{5}$ & 2.1 & 17422 \\
\hline 13 & $\mathrm{CH}_{3}+\mathrm{O} \rightarrow \mathrm{CH}_{2} \mathrm{O}+\mathrm{H}$ & $6.8 \times 10^{13}$ & 0.0 & 0 \\
\hline 14 & $\mathrm{CH}_{2} \mathrm{O}+\mathrm{H} \rightarrow \mathrm{HCO}+\mathrm{H}_{2}$ & $2.5 \times 10^{13}$ & 0.0 & 3991 \\
\hline 15 & $\mathrm{CH}_{2} \mathrm{O}+\mathrm{OH} \rightarrow \mathrm{HCO}+\mathrm{H}_{2} \mathrm{O}$ & $3.0 \times 10^{13}$ & 0.0 & 1195 \\
\hline 16 & $\mathrm{HCO}+\mathrm{H} \rightarrow \mathrm{CO}+\mathrm{H}_{2}$ & $4.0 \times 10^{13}$ & 0.0 & 0 \\
\hline 17 & $\mathrm{HCO}+\mathrm{M} \rightarrow \mathrm{CO}+\mathrm{H}+\mathrm{M}$ & $1.6 \times 10^{14}$ & 0.0 & 14700 \\
\hline 18 & $\mathrm{CH}_{3}+\mathrm{O}_{2} \rightarrow \mathrm{CH}_{3} \mathrm{O}+\mathrm{O}$ & $7.0 \times 10^{12}$ & 0.0 & 25652 \\
\hline 19 & $\mathrm{CH}_{3} \mathrm{O}+\mathrm{H} \rightarrow \mathrm{CH}_{2} \mathrm{O}+\mathrm{H}_{2}$ & $2.0 \times 10^{13}$ & 0.0 & 0 \\
\hline 20 & $\mathrm{CH}_{3} \mathrm{O}+\mathrm{M} \rightarrow \mathrm{CH}_{2} \mathrm{O}+\mathrm{H}+\mathrm{M}$ & $2.4 \times 10^{13}$ & 0.0 & 28812 \\
\hline 21 & $\mathrm{HO}_{2}+\mathrm{HO}_{2} \rightarrow \mathrm{H}_{2} \mathrm{O}_{2}+\mathrm{O}_{2}$ & $2.0 \times 10^{12}$ & 0.0 & 0 \\
\hline $22 f$ & $\mathrm{H}_{2} \mathrm{O}_{2}+\mathrm{M} \rightarrow \mathrm{OH}+\mathrm{OH}+\mathrm{M}$ & $1.3 \times 10^{17}$ & 0.0 & 45500 \\
\hline $22 b$ & $\mathrm{OH}+\mathrm{OH}+\mathrm{M} \rightarrow \mathrm{H}_{2} \mathrm{O}_{2}+\mathrm{M}$ & $9.86 \times 10^{14}$ & 0.0 & -5070 \\
\hline $23 f$ & $\mathrm{H}_{2} \mathrm{O}_{2}+\mathrm{OH} \rightarrow \mathrm{H}_{2} \mathrm{O}+\mathrm{HO}_{2}$ & $1.0 \times 10^{13}$ & 0.0 & 1800 \\
\hline $23 b$ & $\mathrm{H}_{2} \mathrm{O}+\mathrm{HO}_{2} \rightarrow \mathrm{H}_{2} \mathrm{O}_{2}+\mathrm{OH}$ & $2.86 \times 10^{13}$ & 0.0 & 32790 \\
\hline 24 & $\mathrm{OH}+\mathrm{H}+\mathrm{M}^{\mathrm{a}} \rightarrow \mathrm{H}_{2} \mathrm{O}+\mathrm{M}^{\mathrm{a}}$ & $2.2 \times 10^{22}$ & -2.0 & 0 \\
\hline 25 & $\mathrm{H}+\mathrm{H}+\mathrm{M}^{\mathrm{a}} \rightarrow \mathrm{H}_{2}+\mathrm{M}^{\mathrm{a}}$ & $1.8 \times 10^{18}$ & -1.0 & 0 \\
\hline
\end{tabular}
forward and backward reaction rates). According to the applied methods the species

Table 1 - Skeletal mechanism for Methane-Air flames. Units are $m o l, \mathrm{~cm}^{3}, s$ and $K$ (Peters, 1992)

a Third body efficiencies: $\mathrm{CH}_{4}=6.5, \mathrm{H}_{2} \mathrm{O}=6.5, \mathrm{CO}_{2}=1.5, \mathrm{H}_{2}=1.0, \mathrm{CO}=0.75, \mathrm{O}_{2}=0.4, \mathrm{~N}_{2}=0.4$. All other species $=1.0 .{ }^{\mathrm{b}}$ Lindemann form, $k=k_{\infty} /\left(1+k_{f \text { all }} /[M]\right)$ where $k_{f \text { all }}=0.0063 \exp (-1800 / R T)$. 
$0, \mathrm{OH}, \mathrm{HO}_{2}, \mathrm{H}_{2} \mathrm{O}_{2}, \mathrm{CH}_{3} \mathrm{O}$ and $\mathrm{HCO}$ are assumed be in steady-state and, therefore, $w_{s_{i}}=0$, which leads to the following equations among the reaction rates $w_{j}$

$$
\begin{gathered}
w_{24}=w_{1}+w_{2}-w_{3}-2 w_{4}+2 w_{6}-w_{8}-w_{9} \\
-w_{12}-w_{15}+2 w_{22}-w_{23} \\
w_{16}=w_{14}+w_{15}-w_{17} \\
w_{2}=w_{1}+w_{4}-w_{13}+w_{18} \\
w_{7}=w_{5}-w_{6}-w_{8}-2 w_{21}+w_{23} \\
w_{19}=w_{18}-w_{20} \\
w_{22}=w_{21}-w_{23}
\end{gathered}
$$

Making the rates $w_{I}, w_{I I}, w_{I I I}, w_{I V}, w_{V}$ and $w_{V I}$

$$
\begin{gathered}
w_{I}=w_{10}+w_{11}+w_{12} \\
w_{l I}=w_{13}+w_{18} \\
w_{I I I}=w_{14}+w_{15} \\
w_{l V}=w_{9} \\
w_{V I}=2 w_{1}-w_{3}-w_{4}+w_{5}+2 w_{6}-w_{8}-w_{9} \\
w_{V}=w_{1}+w_{6}+w_{18}+w_{21}-w_{23}-w_{12}-w_{15}-w_{17}+2 w_{18} \\
-w_{20}+w_{21}-2 w_{23}+w_{25}
\end{gathered}
$$

results the following linear combinations

$$
\begin{gathered}
w_{\mathrm{O}_{2}}=-w_{V} \\
w_{\mathrm{CH}_{4}}=-w_{I} \\
w_{\mathrm{CO}_{2}}=w_{I V} \\
w_{\mathrm{H}_{2} \mathrm{O}}=-w_{I I}-w_{I V}+2 w_{V} \\
w_{C O}=w_{I I I}-w_{I V} \\
w_{H_{2}}=w_{I}+w_{I I}+2 w_{I I I}+w_{I V}-3 w_{V}+w_{V I} \\
w_{C_{2} O}=w_{I I}-w_{I I I} \\
w_{C_{3}}=w_{I}-w_{I I} \\
w_{H}=-w_{I}+w_{I I}-2 w_{I I I}+2 w_{V}-2 w_{V I}
\end{gathered}
$$

The stoichiometry of these balance equations correspond to the global mechanism of six-step for the methane formed by reactions I to VI, as follows

$$
\begin{array}{lc}
\text { I } & \mathrm{CH}_{4}+\mathrm{H} \rightarrow \mathrm{CH}_{3}+\mathrm{H}_{2} \\
\text { II } & \mathrm{CH}_{3}+\mathrm{H}_{2} \mathrm{O} \rightarrow \mathrm{CH}_{2} \mathrm{O}+\mathrm{H}_{2}+\mathrm{H} \\
\text { III } & \mathrm{CH}_{2} \mathrm{O}+2 \mathrm{H} \rightarrow \mathrm{CO}+2 \mathrm{H}_{2} \\
\text { IV } & \mathrm{CO}+\mathrm{H}_{2} \mathrm{O} \rightarrow \mathrm{CO}_{2}+\mathrm{H}_{2} \\
\text { V } & 3 \mathrm{H}_{2}+\mathrm{O}_{2} \rightarrow 2 \mathrm{H}+2 \mathrm{H}_{2} \mathrm{O} \\
\text { VI } & \mathrm{H}+\mathrm{H}+\mathrm{M} \rightarrow \mathrm{H}_{2}+\mathrm{M}
\end{array}
$$

\subsection{Other Considerations}

Each technique for mechanisms reduction presented in this paper has its advantages and drawbacks. The chemical-based approach of lumping requires extensive chemical expertise, while formal methods have quite stringent mathematical restrictions that make its wide application difficult. Discussions about this subject are presented in the literature, as in Huang et al. (2005). The lumping technique has been widely used for lumping of isomers.

The DRG technique is very simple, of easy automation and has low computational cost, with the disadvantage that it is only effective for obtaining skeletal mechanisms from detailed mechanisms. Although recent, the technique has already been used successfully by several authors for mechanisms reduction (e.g. Lu and Law (2006a) or Xin et al. (2008)).

Sensitivity analysis is a powerful tool that can be used in the identification of redundant reactions or species. The point is that the technique, when associated to the solution of the set of differential equations (1), as in the case of the PCA of matrix $S$, may not be feasible due to the large number of variables.

In short, the techniques for kinetic mechanisms reduction are based on the

a) degree of relationship between species;

b) sensitivity of the system variables in relation to parameters; or

c) analysis of time scales in order to reduce the system's stiffness by eliminating some variables.

What seems to be the best strategy is to combine different techniques. This idea has been used by several authors (see e.g., Li and Rabitz (1996); Pepiot-Desjardins and Pitsch (2008a); Hughes et al. (2009); Niemeyer et al. (2010); or Shi et al. (2010)).

Other formal techniques, such as Computational Singular Perturbation (CSP) (Lam and Goussis, 1989; 1992; 1993; 1994) and Intrinsic Low-Dimensional manifolds (ILDM's) (Maas and Pope, 1992a; 1992b; 1994), have been developed, and also applied, as in Valorani et al. (2006), Bauer et al. (2006) and Prager et al. (2009), for obtaining reduced mechanisms. In these techniques, the determination of eigenvalues (and eigenvectors) is also required. According to Datta (2010) and Golub and Van Loan (2013), the work of finding eigenvalues and eigenvectors is computationally more successful (and practicable) using the QR iteration method. However, in order to reduce computational time, such task should be optimized by, for example, measuring the possibility of implementation of QR iteration using Givens rotations, as raised in Vandebril (2011).

\section{Conclusions}

This paper has summarized, in a simple and brief way, some techniques that can be used in the kinetic mechanisms reduction for 
combustion. A reduced mechanism for methane flames was obtained, which is in agreement with data found in the literature.

One of the main objectives of reducing mechanisms is minimize computational effort. Therefore, it is necessary to have enough knowledge on the subject so that the tools used in the mechanisms reduction do not become computationally prohibitive. The best strategy seems to be to combine different techniques, benefiting up of advantages of each one. This requires the mastery of mathematical concepts involved as well as an understanding on the chemical-physical issue.

\section{Acknowledgements}

This research is being developed at UFRGS, Universidade Federal do Rio Grande do Sul. Bublitz thanks the financial support from CAPES Coordenação de Aperfeiçoamento de Pessoal de Nível Superior. Prof. De Bortoli gratefully acknowledges the financial support from $\mathrm{CNPq}$ Conselho Nacional de Desenvolvimento Científico e Tecnológico, under the process 304798/2012-6.

\section{References}

ANDREIS, G. S. L.; DE BORTOLI, A. L. LES solution of a methanol jet diffusion flame. In: 14th Brazilian Congress of Thermal Sciences and Engineering, 2012, Rio de Janeiro. Proceedings of the ENCIT 2012, 2012, p. 1-8.

ANDREIS, G. S. L.; GOMES, R. S.; DE BORTOLI, A. L. A reduced kinetic mechanism for propane flames. Engenharia Térmica 11, 2012, p. 37-43.

ANDREIS, G. S. L.; VAZ, F. A.; DE BORTOLI, A. L. Bioethanol combustion based on a reduced kinetic mechanism. Journal of Mathematical Chemistry 51, 2013, p. 1584-1598.

AN, J.; JIANG, Y. Differences between direct relation graph and error-propagation-based reduction methods for large hydrocarbons. Procedia Engineering 62, 2013, p. 342-349.

BAUER, J.; BYKOV, V.; MAAS, U. Implementation of ILDMs based on a representation in generalized coordinates. In: ECCOMAS CFD 2006: Proceedings of the European Conference on Computational Fluid
Dynamics, Egmond aan Zee, The Netherlands, 2006.

Datta, B. N. Numerical Linear Algebra and Applications, $2^{\text {nd }}$ ed. SIAM, 2010.

DE BORTOLI, A. L.; ANDREIS, G. S. L.; PEREIRA, F. N. Modeling and Simulation of Reactive Flows. Elsevier Science Publishing Co Inc, 2015.

DE BORTOLI, A. L. Introdução à Dinâmica de Fluidos Computacional. $1^{\text {st }}$ ed. Porto Alegre: Editora da UFRGS, 2000.

GOLUB, G.; VAN LOAN, C. Matrix Computations. $4^{\text {th }}$ ed. The Hopkins University Press, Baltimore, Maryland, 2013.

GOUSSIS, D. A.; LAM, S. H. A study of homogeneous methanol oxidation kinetics using CSP. In: Symposium (International) on Combustion 24(1). Elsevier, 1992, p. 113-120.

GRIFFITHS, J. F. Reduced kinetic models and their application to practical combustion systems. Progress in Energy and Combustion Science 21, 1995, p. 25-107.

HUANG, H. ET AL. A systematic lumping approach for the reduction of comprehensive kinetic models. Proceedings of the Combustion Institute 30(1), 2005, p. 1309-1316.

HUGHES, K. J. et al. The application of the QSSA via reaction lumping for the reduction of complex hydrocarbon oxidation mechanisms. Proceedings of the Combustion Institute 32(1), 2009, p. 543-551.

KUO, J. C. W.; WEI, J. Lumping analysis in monomolecular reaction systems. Analysis of approximately lumpable system. Industrial \& Engineering Chemistry Fundamentals 8(1), 1969a, p. 124-133.

KUO, J. C. W.; WEI, J. Lumping analysis in monomolecular reaction systems. Analysis of the exactly lumpable system. Industrial \& Engineering Chemistry Fundamentals 8(1), 1969b, p. 114-123.

KUO, K. Principles of Combustion. $2^{\text {nd }}$ ed. John Wiley \& Sons, Inc., 2005.

LAM, S. H.; GOUSSIS, D. A. The CSP method for simplifying kinetics. International Journal of Chemical Kinetics 26(4), 1994, p. 461-486. 
LAM, S. H.; GOUSSIS, D. A. Understanding complex chemical kinetics with computational singular perturbation. In: Symposium (International) on Combustion. Elsevier, 1989, p. 931-941.

LAM, S. H. Using CSP to understand complex chemical kinetics. Combustion Science and Technology 89(5-6), 1993, p. 375-404.

LI, G.; RABITZ, H. A general analysis of approximate lumping in chemical kinetics. Chemical Engineering Science. 45(4), 1990, p. 977-1002.

LI, G.; RABITZ, H. A general analysis of exact lumping in chemical kinetics. Chemical Engineering Science. 44(6), 1989, p. 1413-1430.

LI, G.; RABITZ, H. Combined symbolic and numerical approach to constrained nonlinear lumping - With application to an $\mathrm{H} 2 / \mathrm{O} 2$ oxidation model. Chemical Engineering Science 51(21), 1996, p. 4801-4816.

LU, T.; LAW, C. K. A directed relation graph method for mechanism reduction. Proceedings of the Combustion Institute 30(1), 2005, p. 13331341.

LU, T.; LAW, C. K. Linear time reduction of large kinetic mechanisms with directed relation graph: n-heptane and iso-octane. Combustion and Flame 144(1), 2006a, p. 24-36.

LU, T.; LAW, C. K. On the applicability of directed relation graphs to the reduction of reaction mechanisms. Combustion and Flame 146(3), 2006b, p. 472-483.

MAAS, U.; Pope, S. B. Implementation of simplified chemical kinetics based on intrinsic low-dimensional manifolds. In: Symposium (International) on Combustion. Elsevier, 1992a, p. 103-112.

MAAS, U.; POPE, S. B. Laminar flame calculations using simplified chemical kinetics based on intrinsic low-dimensional manifolds. In: Symposium (International) on Combustion. Elsevier, 1994, p. 1349-1356.

MAAS, U.; POPE, S. B. Simplifying chemical kinetics: intrinsic low-dimensional manifolds in composition space. Combustion and Flame 88(3), 1992b, p. 239-264.
MARTINS, I. P. Redução sistemática de mecanismos cinéticos de combustão. Dissertação de Mestrado - UFRGS, 2011.

NIEMEYER, K. E.; SUNG, C. J.; RAJU, M. P. SKELETAL mechanism generation for surrogate fuels using directed relation graph with error propagation and sensitivity analysis. Combustion and Flame 157(9), 2010, p. 1760-1770.

PETERS, N. Fifteen lectures on laminar and turbulent combustion. Ercoftac Summer School, 1992.

PETERS, N.; ROGG, B. Reduced Kinetic Mechanisms for Applications in Combustion Systems, Lecture Notes in Physics, SpringerVerlag, Berlin, 1993.

PEPIOT-DESJARDINS, P.; PITSCH, H. An automatic chemical lumping method for the reduction of large chemical kinetic mechanisms. Combustion Theory and Modelling 12(6), 2008a, p. 1089-1108.

PEPIOT-DESJARDINS, P.; PITSCH, H. An efficient error-propagation-based reduction method for large chemical kinetic mechanisms. Combustion and Flame 154(1), 2008b, p. 67-81.

PRAGER, J. ET AL. Skeletal mechanism generation with CSP and validation for premixed n-heptane flames. Proceedings of the Combustion Institute 32(1), 2009, p. 509-517.

RANZI, E. ET AL. Lumping procedures in detailed kinetic modeling of gasification, pyrolysis, partial oxidation and combustion of hydrocarbon mixtures. Progress in Energy and Combustion Science 27(1), 2001, p. 99-139.

SHI, Y. ET AL. Automatic chemistry mechanism reduction of hydrocarbon fuels for $\mathrm{HCCI}$ engines based on DRGEP and PCA methods with error control. Energy \& Fuels, 24(3), 2010, p. 1646-1654.

STAGNI, A. ET AL. Lumping and reduction of detailed kinetic schemes: an effective coupling. Industrial \& Engineering Chemistry Research 53(22), 2014, p. 9004-9016.

TOMLIN, A.; TURÁNYI, T.; PILLING, M. Mathematical tools for construction, investigation and reduction of combustion mechanisms. Elsevier, Amsterdam, 1998. 
TURÁNYI, T. Applications of sensitivity analysis to combustion chemistry. Reliability Engineering \& System Safety 57(1), 1997, p. 41-48.

TURÁNYI, T., BERCES, T.; VAJDA, S. Reaction rate analysis of complex kinetic systems. International Journal of Chemical Kinetics 21(2), 1989, p. 83-99.

TURÁNYI, T. Sensitivity analysis of complex kinetic systems. Tools and applications. Journal of Mathematical Chemistry 5(3), 1990, p. 203-248.

TURÁNYI, T.; TOMLIN, A. S. Analysis of Kinetic Reaction Mechanisms. Springer, 2014.

TURNS, S. An Introduction to Combustion: Concepts and Applications, $2^{\text {nd }}$ ed. McGraw-Hill Hight Education, 2000.

VAJDA, S.; VALKO, P.; TURANYI, T. Principal component analysis of kinetic models. International Journal of Chemical Kinetics 17(1), 1985. p. 55-81.

VALORANI, M. ET AL. An automatic procedure for the simplification of chemical kinetic mechanisms based on CSP. Combustion and Flame 146(1), 2006, p. 29-51.

VANDEBRIL, R. Chasing bulges or rotations? A metamorphosis of the QR-algorithm. SIAM Journal on Matrix Analysis and Applications 32(1), 2011, p. 217-247.

WHITEHOUSE, L. E.; TOMLIN, A. S.; PILLING, M. J. Systematic reduction of complex tropospheric chemical mechanisms, Part I: sensitivity and time-scale analyses. Atmospheric Chemistry and Physics 4(7), 2004a, p. 2025-2056.

WHITEHOUSE, L. E.; TOMLIN, A. S.; PILLING, M. J. Systematic reduction of complex tropospheric chemical mechanisms, Part II: lumping using a time-scale based approach. Atmospheric Chemistry and Physics 4(7), 2004b, p. 2057-2081.

XIN, Y. ET AL. The directed relation graph method for mechanism reduction in the oxidative coupling of methane. Catalysis Today 131(1), 2008, p. 483-488.

ZHENG, X. L.; LU, T. F.; LAW, C. K. Experimental counterflow ignition temperatures and reaction mechanisms of 1, 3-butadiene. Proceedings of the Combustion Institute 31(1), 2007, p. 367-375. 